\title{
Siting of Wood Pellet Production Facilities in Environmental Justice Communities in the Southeastern United States
}

\author{
Stefan Koester and Sam Davis
}

\begin{abstract}
As efforts to decarbonize the electric sector take on increased urgency, governments are turning to wood pellets as a potential renewable energy resource. However, the production of pellets from woody biomass has immediate community-wide impacts on air and water quality. This article investigates the siting of wood pellet production facilities in the southeastern United States and finds that they are $50 \%$ more likely to be located in environmental justice (EJ)-designated communities. We define an EJ community as a county where the poverty level is above the state median and at least $25 \%$ of the population is nonwhite. In addition, we find that all biomass pellet mills in North Carolina and South Carolina are in EJ communities. There is a longstanding history of EJ communities being disproportionately targeted for the siting of coal and natural gas power plants, in addition to waste-to-energy plants and landfills. Wood pellet production facilities are similar to these plants in their emissions of harmful particulate matter, airborne pollutants such as carbon monoxide, carbon dioxide, nitrogen oxides, sulfur oxides, and their degradation of local water quality. Wood pellet production is increasing rapidly in the southeastern United States. These data add to growing evidence that biomass pellet mills in the southeastern United States place an undue burden on economically depressed areas of color.
\end{abstract}

Keywords: biomass, environmental justice, southeastern United States

\section{INTRODUCTION}

$\mathbf{T}$ HE SYSTEMATIC PATTERN of wood pellet production facilities being sited and located in environmental justice (EJ) communities in the southeastern United States is the focus of this article. By analyzing publicly available census track data and production facility locations, we compiled data that investigate whether or not

Mr. Stefan Koester is a Dual Master's Candidate at the Fletcher School of Law and Diplomacy and the Urban and Environmental Policy \& Planning Program at Tufts University in Medford, Massachusetts. Dr. Sam Davis is Research Manager at Dogwood Alliance in Asheville, North Carolina.

(C) Koester and Davis, 2017; Published by Mary Ann Liebert, Inc. This Open Access article is distributed under the terms of the Creative Commons Attribution Noncommercial License (http://creativecommons.org/licenses/by-nc/4.0/) which permits any noncommercial use, distribution, and reproduction in any medium, provided the original author(s) and the source are credited. wood pellet production facilities are more likely to be located in EJ communities than non-EJ communities. The nine states of interest in the southeast are Alabama, Arkansas, Florida, Georgia, Louisiana, Mississippi, North Carolina, South Carolina, and Virginia. We found that EJ communities in these nine states were roughly twice as likely to have a wood pellet production facility in their community than non-EJ communities. This creates and perpetuates circumstances in which vulnerable and economically depressed communities bear the burden of energy development projects, while powerful outside entities benefit from cheap labor and capital costs, in addition to generous subsidies from states and the federal government.

The existing literature on EJ communities is robust, as is the literature on the environmental and health impacts of biomass production. However, with the exception of Booth, Shrader-Frechette, and Preisser, and Mittlefehldt and Tedford, which focus on biomass facilities for heat and electricity production and EJ communities in 
Pennsylvania, Indiana, and Vermont, respectively, little research has focused on the southeastern United States, an area where a majority of national production capacity for wood pellets is located. ${ }^{1,2,3}$

The production of woody biomass pellets is an energy intensive process that includes shipping logs and other raw material to the production facility, usually through truck or rail; processing through chipping, drying, grinding, and pelleting machines; and finally bagging and shipping, again, usually through truck and rail to international export terminals. ${ }^{4}$ In $2016,>99 \%$ of the wood pellet exports to the EU originated from southeastern U.S. ports. ${ }^{5}$ Owing to the high economic costs of shipping whole trees and forest residue, most input materials are sourced from within a 75 -mile radius of the processing facility. ${ }^{6}$

In addition, biomass and coal are usually burned onsite to generate the needed electricity to fuel the plants. Throughout this process, emissions from shipping and processing are generated, along with increased road and rail traffic, noise pollution, and degradation of regional water quality and ecosystem services, all of which impact the populations in the surrounding areas.

The National Association for the Advancement of Colored People (NAACP) found that African Americans who live near biomass power plants are more likely to suffer from increased exposure to a number of dangerous emissions, such as smog, asbestos, sulfur dioxide, and other toxins, than any other racial group in America. ${ }^{7}$ For this reason, a number of southern chapters of the NAACP opposed the siting of wood pellet production facilities in their communities, with one Georgia chapter stating that the siting of a wood pellet production facility in their community was "a clear cut example of environmental racism." 8

This article is laid out as follows: Framing EJ in the Southeast section frames the issue of EJ in southeastern United States and defines the term as it is commonly

\footnotetext{
${ }^{1}$ Mary S. Booth. "Biomass Energy in Pennsylvania: Implication for Air Quality, Carbon Emissions and Forests," (Partnership for Public Integrity, Dec 2012).

${ }^{2}$ Shrader-Frechette and Whitney C. Preisser. "Renewable Technologies and Environmental Injustice: Subsidizing Bioenergy, Promoting Inequity." Environmental Justice 6 (2013): 88-93.

${ }^{3}$ Sarah Mittlefehldt and Codie Tedford. "Benefit or Burden? Environmental Justice and Community-Scale Biomass Energy Systems in Vermont." Environmental Justice 6 (2014): 110-114.

${ }^{4}$ Jeremy Fisher, Sarah Jackson, and Bruce Biewald. "The Carbon Footprint of Electricity from Biomass: A Review of the Current State of Science and Policy," (Synapse Energy Economics White Paper, June 11, 2012).

${ }^{5}$ Andrew Copley. U.S. Wood Pellet Exports Weigh Anchor in 2016, Froisk Blog. <http://forisk.com/blog/2017/04/07/u-s-woodpellet-exports-weigh-anchor-2016>. (Last accessed on June 21, 2017).

${ }^{6}$ Natural Resources Defense Council, "In the U.S. Southeast, Natural Forests Are Being Felled to Send Fuel Overseas," NRDC Report (October 2015).

${ }^{7}$ National Association for the Advancement of Colored People (NAACP), "Just Energy Policies: Reducing Pollution and Creating Jobs," Cleveland, Ohio, (2013): 5.

${ }^{8}$ Ronnie Greene. " 'Green' Biomass Isn't Always So Clean," The Center for Public Integrity (April 26, 2011).
}

used; Wood Pellet Production Facilities section presents some of the dangers that wood pellet production facilities pose to local communities; Methodology section lays out our methodology for determining whether or not a community is an EJ community; Data section presents results from a chi-squared analysis; Results and Discussion section discusses our results; A Contemporary Case section highlights a contemporary case in Richmond County, North Carolina, where residents are fighting the siting of a woody biomass pellet production facility in their community; finally we conclude in Conclusion section.

\section{FRAMING EJ IN THE SOUTHEAST}

EJ scholars have shown that economically depressed communities of color shoulder disproportionate environmental and health burdens when it comes to the siting of hazardous waste sites, landfills, and fossil fuel plants. The history of EJ has roots in the southeastern United States. In 1982, in Warren County, North Carolina, plans to deposit 40,000 tons of soil contaminated with polychlorinated biphenyl (PCB), a known toxic substance, were drawn up by the state. Proposals for the 143-acre PCB landfill in Afton, a rural town in Warren County that was $84 \%$ black with per capita incomes of $\$ 6984$, compared with $\$ 9283$ for the state overall, were met with strong resistance from the local community. ${ }^{9}$

Although ultimately unsuccessful, town residents mobilized opposition around the toxic landfill through a series of nonviolent, civil disobedience actions, including a 6-week opposition to the trucking in of 7097 truckloads of contaminated soil. ${ }^{10}$ Residents argued that their community was chosen as the location for the toxic landfill, not because the site was the safest, most suitable, or even cheapest location, but rather because their community was politically and economically disenfranchised, and would therefore, be an easier community in which the state could locate the landfill. ${ }^{11}$

In 1987, the United Church of Christ, an organization involved in the Warren County, PCB landfill struggle, published the first report proving that race was among the most significant variables associated with the location of hazardous waste sites throughout the United States, with targeted communities having twice the average percentage of minority residents than communities without hazardous waste sites. ${ }^{12}$ A follow-up report published 20

\footnotetext{
${ }^{9}$ Robert D. Bullard. "Environmental Justice in the TwentyFirst Century." In The Quest for Environmental Justice, edited by Robert D. Bullard. (San Francisco: Sierra Club Press, 2005), $19-42$.

${ }^{10}$ Eileen M. McGurty. Transforming environmentalism: Warren County, PCBs, and the Origin of Environmental Justice. (New Brunswick: Rutgers University Press, 2007).

${ }^{11}$ Eileen M. McGurty. Transforming environmentalism: Warren County, PCBs, and the Origin of Environmental Justice. (New Brunswick: Rutgers University Press, 2007).

${ }^{12}$ Commission for Racial Justice, United Church of Christ, "Toxic Wastes and Race in the United States: A National Report on the Racial and Socio-Economic Characteristics of Communities with Hazardous Waste Sites," (Prepared by Public Data Access, Inc., 1987).
} 
years later found that little had changed, noting that the majority of hazardous waste sites in the country are sited in neighborhoods with majority nonwhite populations. ${ }^{13}$

As the case of Warren County illustrates, making claims of EJ requires more than just the uncovering and presentation of evidence that a community has been the victim of an environmental wrongdoing. Rather, EJ requires both an evidence-based finding with a normative judgment that a community has been the victim of an injustice. ${ }^{14}$ Therefore, a standard of justice is necessary to determine how and in what way a community's right to justice has been violated.

There are a number of definitions in both the academic literature and regulatory statutes for the term "environmental justice." Although they are all slightly different, the common components include equal protection and fair treatment regardless of race, economic status, or geographic location with regard to the "development, implementation, and enforcement of environmental law, regulations, and policies." ${ }^{15}$ In addition, a number of definitions cite the equal right to a healthy and just environment. ${ }^{16}$ These definitions serve as the normative grounding for our use of the term "environmental justice" in this article. Communities must have access to distributional justice through the equal right to healthy and livable environments, in addition to procedural justice through equal protection and fair treatment of a community regardless of race, economic status, or geographic location. Finally, communities must have meaningful involvement in decision making to ensure process justice. $^{17}$

We define EJ communities as a county that has a nonwhite population over $25 \%$, and an average poverty level for all age groups above the state median. This definition is used by the state of Massachusetts to establish quantitative parameters for designating EJ communities. ${ }^{18}$ Although this definition is limited in that it is solely a quantitative measure, it serves as a useful metric to capture a wide geographic area. A Contemporary Case section provides experiential and qualitative evidence from a contemporary instance of a wood pellet production facility in an EJ community.

\section{WOOD PELLET PRODUCTION FACILITIES}

Woody biomass is an energy-lite resource that some policy makers consider renewable due to the regenerative,

\footnotetext{
${ }^{13}$ Robert D. Bullard, et al. Toxic Wastes and Race at Twenty: 1987-2007. (United Church of Christ, 2007).

${ }^{14}$ Gordon Walker. Environmental Justice: Concepts, Evidence and Politics. (London: Routledge Press, 2012).

${ }^{15}$ United States EPA. Environmental Justice. <https://www.epa .gov/environmentaljustice $>$. (Last accessed on June 21, 2017).

${ }^{16}$ Gordon Walker. Environmental Justice: Concepts, Evidence and Politics. (London: Routledge Press, 2012).

${ }^{17}$ Kristin Shrader-Freechette. Environmental Justice: Creating Equality, Reclaiming Democracy. (New York: Oxford University Press, 2002).

${ }^{18}$ The Massachusetts Executive Office of Energy and Environmental Affairs. MassDEP Environmental Justice. <http://www .mass.gov/eea/agencies/massdep/service/justice>. (Last accessed on June 21, 2017).
}

carbon sequestering features of forests. Although the EPA does not consider all biomass to be carbon neutral, the energy resource is able to benefit from generous federal renewable energy tax credits. ${ }^{19}$ Wood pellet production facilities, however, present a danger to human health due to the high levels of ambient air pollution, and other deleterious effects, such as increased lower respiratory infections in young children and chronic obstructive pulmonary disease. ${ }^{20}$ In addition, biomass releases more carbon dioxide per unit of energy generated and releases 25 times more fine particulate matter, a proven cause of respiratory illnesses in children, including asthma, than comparable coal-fired plants. ${ }^{21}$

According to the Energy Information Administration (EIA), the United States biomass manufacturing capacity is currently at 13 million tons per year, with $75 \%$ of that capacity located in the south. ${ }^{22}$ Plants in the southeast produced more than 9.6 million dry tons of wood pellets in 2015 , with exports from the region expected to increase from 10.6 million tons in 2019 to more than 15 million tons by $2030 .{ }^{23}$ As global demand for wood pellets increases, pellet companies are expanding operations, with almost 1 million tons of processing capacity either planned or under construction. ${ }^{24}$

The EIA estimates that biomass energy could produce $15 \%$ of United States energy needs by 2035, up from $8 \%$ in $2009 .{ }^{25}$ Of the 37 wood pellet production facilities that are either in operation or under construction in our nine southern states of interest, with an annual production capacity of at least 50,000 tons per year, average annual capacity is more than 250,000 tons, with some as large as 825,000 tons per year. By our estimate, to meet this demand, the average plant would require more than 6000 acres annually of local forest as supply inputs. ${ }^{26}$

\footnotetext{
${ }^{19}$ United States EPA. Biomass Heating and Cooling Technologies. <https://www.epa.gov/rhc/biomass-heating-and-coolingtechnologies>. (Last accessed on June 21, 2017).

${ }^{20}$ Tobern Sigsgaard, et al. "Health Impacts of Anthropogenic Biomass Burning in the Developed World." European Respiratory Journal 46 (2015): 1557-1588.

${ }^{21}$ Jeremy Fisher, Sarah Jackson, and Bruce Biewald. "The Carbon Footprint of Electricity from Biomass: A Review of the Current State of Science and Policy," (Synapse Energy Economics White Paper, June 11, 2012).

${ }^{22}$ United States Energy Information Administration. Monthly Densified Biomass Fuel Report. <https://www.eia.gov/biofuels/ biomass $>$. (Last accessed on June 21, 2017).

${ }^{23}$ Seth Walker, Chris Lyddan, William Perritt, and Lori Pilla. 2015. An Analysis of UK Biomass Power Policy, US South Pellet Production and Impacts on Wood Fiber Markets: Prepared for the American Forest \& Paper Association. (Boston: RISI, 2015). $<$ www.risi.com $>$. Last accessed June 21, 2017.

${ }^{24}$ United States Energy Information Administration. Monthly Densified Biomass Fuel Report. <https://www.eia.gov/biofuels/ biomass $>$. (Last accessed on June 21, 2017).

${ }^{25}$ United States Energy Information Administration. Office of Energy Statistics. 2011 Annual Energy Review 2010. <https:// www.eia.gov/totalenergy/data/annual $>$. (Last accessed on June 21, 2017).

${ }^{26}$ Total acres harvest $=([$ Biomass plant capacity in tons per year $\cdot 0.52$ [weighted average of plant capacity to harvested wood by type] - 3.274 [ratio of green tons of harvested wood to dry tons] $/ 70.15$ [weighted average total number of tons per acre over average life of the stand] 6066.99 acres $=((250,000$. $0.52) \times 3.274) / 70.15)$ ).
} 
Reducing local forest cover impacts human health by reducing the positive air and water quality benefits that local forests provide. For example, forested land absorbs twenty times more water during storm events than a parking lot, and six times more than a residential lawn. ${ }^{27}$ A correlative study in the Midwest found that rates of heart disease and lower respiratory illness increased after emerald ash borer devastated ash trees in the region. ${ }^{28}$ In the conterminous United States, trees remove up to 23.2 million tons per year of air pollutants, while forested rural areas remove roughly 25 times more pollution than urban areas. ${ }^{29}$ These studies, in combination with others, show the positive health benefits of forested areas, and demonstrate that deforestation in the surrounding area of wood pellet production facilities further burdens EJ communities.

Biomass pellet manufacturing is an energy intense process that has high transportation, processing, and shipping emissions. ${ }^{30}$ These include emissions from logging operations, transportation, chipping and pelleting, and finally, transportation to end-use consumers. In addition, there are significant inputs, from fertilizer to fossil fuels in the production process. Although comprehensive life-cycle analysis of biomass production and consumption is inconclusive, there is evidence that the resulting emissions from biomass pellet production are substantial. ${ }^{31,32}$

A majority of wood pellet production facilities burn biomass and coal on-site to power plant processing operations. ${ }^{33}$ This invariably leads to significant emissions within the local vicinity of the plant. Numerous studies linked the burning of biomass to increased particulate matter concentrations, a key cause of acute and chronic respiratory illnesses, particularly within young and el-

\footnotetext{
${ }^{27}$ David N. Wear and John G. Greis. "Southern Forest Resource Assessment-Technical Report." Gen. Tech. Rep. SRS-53. (Asheville, NC: US Department of Agriculture, Forest Service, Southern Research Station), 635, 53.

${ }^{28}$ Geoffrey H. Donovan, David T. Butry, Yvonne L. Michael, Jeffrey P. Prestemon, Andrew M. Liebhold, Demetrios Gatziolis, and Megan Y. Mao. "The Relationship Between Trees and Human Health: Evidence from the Spread of the Emerald Ash Borer." American Journal of Preventive Medicine 44 (2013): 139-145.

${ }^{29}$ David J. Nowak, Satoshi Hirabayashi, Allison Bodine, and Eric Greenfield. "Tree and Forest Effects on Air Quality and Human Health in the United States." Environmental Pollution 193 (Oct 2014): 119-129.

${ }^{30}$ Jeremy Fisher, Sarah Jackson, and Bruce Biewald. "The Carbon Footprint of Electricity from Biomass: A Review of the Current State of Science and Policy," (Synapse Energy Economics White Paper, June 11, 2012).

${ }^{31}$ Roger A. Sedjo. "Comparative Life Cycle Assessments: Carbon Neutrality and Wood Biomass Energy," (Resources for the Future Discussion Paper 13-11, April 2013).

${ }^{32}$ Mary S. Booth. "Biomass Energy in Pennsylvania: Implication for Air Quality, Carbon Emissions and Forests," (Partnership for Public Integrity, 2012).

${ }^{33}$ Jeremy Fisher, Sarah Jackson, and Bruce Biewald. "The Carbon Footprint of Electricity from Biomass: A Review of the Current State of Science and Policy," (Synapse Energy Economics White Paper, June 11, 2012).
}

derly populations. ${ }^{34,35}$ In addition, one study found a statistically significant relationship between exposure to PM 2.5 and a $6.8 \%$ increase in the risk of premature birth in North Carolina mothers. ${ }^{36}$ It is for these reasons that the American Lung Association and the American Heart Association, along with dozens of other public health, medical, and nursing organizations, oppose the expanded use and construction of wood pellet production facilities. $^{37,38}$

\section{METHODOLOGY}

With much of the United States biomass manufacturing capacity located in the southeast, we focused on the 793 counties in nine states of interest: Alabama, Arkansas, Georgia, Florida, Louisiana, Mississippi, North Carolina, South Carolina, and Virginia. Using 2015 American Community Survey data from the U.S. Census Bureau, we compiled population, income, and racial demographic information for all 793 counties.

Using publicly available information found on the biomass industry trade website, we located 32 biomass processing facilities that are either built or under construction and located in our nine states of interest. ${ }^{39}$ Plants with an annual capacity of less than 50,000 tons were excluded from our sample. We then created binary variables for whether or not a county represented an EJ county. Finally, we used a chi-square test of independence between wood pellet production facility locations and EJ communities to determine the likelihood that a woody biomass pellet facility is located in an EJ community.

\section{DATA}

We found that of the 793 counties in our nine states of interest, there are 282 counties that meet our definition of an EJ community. Of the 32 wood pellet production facilities, we found that 18 were located in EJ communities,

\footnotetext{
${ }^{34}$ Tobern Sigsgaard, et al. "Health Impacts of Anthropogenic Biomass Burning in the Developed World." European Respiratory Journal 46 (2015): 1557-1588.

${ }^{35}$ Christoffer Boma, et al. "Adverse Health Effects from Ambient Air Pollution in Relation to Residential Wood Combustion in Modern Society." Scandinavian Journal of Work, Environment \& Health 28 (2003): 251-260.

${ }^{36}$ Howard H. Chang, et al. "Time-to-Event Analysis of Fine Particle Air Pollution and Preterm Birth: Results from North Carolina, 2001-2005." American Journal of Epidemiology 175 (2012): 91-98.

${ }^{37}$ American Lung Association, et al. "Health Organizations' Letter on the Health Impacts of Biomass," Letter to Senators and Representatives, September 13, 2016. <http://www.lung .org/assets/documents/advocacy-archive/health-organizationsletter-biomass.pdf>. Last accessed June 21, 2017.

${ }^{38}$ Robert D. Brook, et al. "Particulate Matter Air Pollution and Cardiovascular Disease an Update to the Scientific Statement from the American Heart Association," Circulation 121 (2010): 2331-2378.

${ }^{39}$ U.S. Pellet Plants, Biomass Magazine. <http://biomass magazine.com/plants/listplants/pellet/US/Operational>. (Last accessed June 21, 2017).
} 


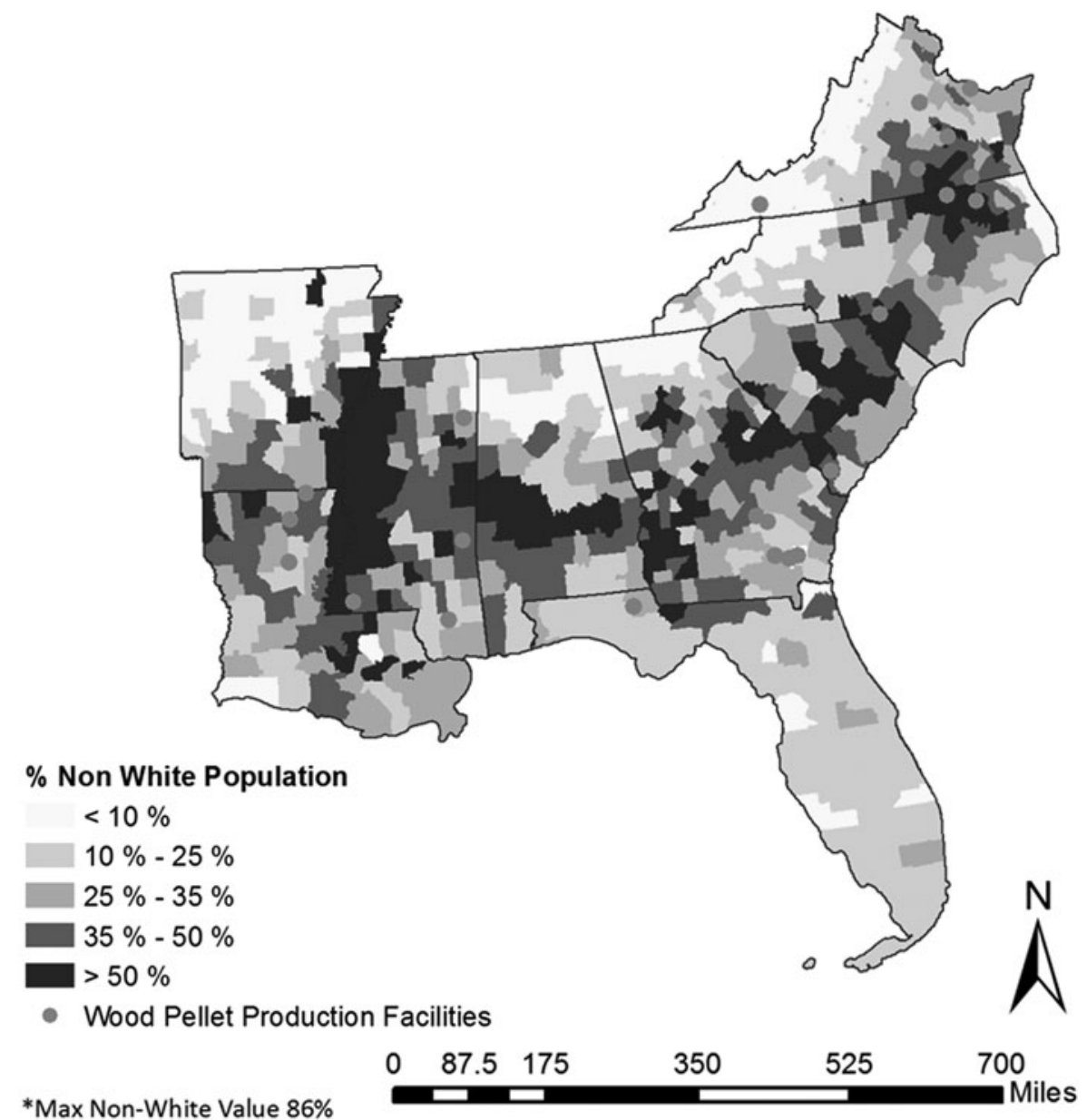

FIG. 1. Percentage nonwhite population by county. with an additional 3 facilities located within 4 miles of an EJ community. We mapped our variables of interest and located EJ communities. Figure 1 depicts the percentage of nonwhite residents in all 793 southeastern counties; Figure 2 illustrates the percentage of residents living below the state median income in all 793 southeastern counties, and Figure 3 highlights defined EJ communities. In all three figures, the dots represent the 27 wood pellet production facilities of interest that are operating, but not those that are under construction or planned.

\section{RESULTS AND DISCUSSION}

We conducted a chi-squared analysis of independence to determine the likelihood that a biomass pellet facility is located in an EJ-designated community. We found a statistically significant result, at the 5\% level, showing that the relationship between a wood pellet production facility location and EJ community is not independent of each other. In addition, we found that given it was an EJ community, there was a $53 \%$ greater chance that there was a biomass plant located in that community. Finally, we found that all wood pellet production facilities in North Carolina and South Carolina are located in EJdesignated communities.

\section{A CONTEMPORARY CASE}

In 2014, the Richmond County Bureau of Economic Development, along with Governor Pat McCrory and Enviva Pellets Hamlet, LLC, announced plans to build a biomass pellet manufacturing plant in Hamlet, North Carolina, a town with less than 6500 residents in the south-central part of the state. The Enviva plant is the beneficiary of $\$ 1.7$ million in state and local tax credit subsidies. ${ }^{40}$ The announcement touted the estimated $\$ 107$ million in planned investment and hiring of 79 employees. $^{41}$

What the joint press release neglected to mention were the potentially detrimental effects to human health, wellbeing, and the environment that this biomass pellet facility would bring to the community. Hamlet, according to the EPA's EJSCREEN tool, is in the 70th to 90th

\footnotetext{
${ }^{40}$ Office of Governor Pat McCrory "Envvia to Develop 2 Pellet Plants in North Carolina." Biomass Magazine (September 10, 2014).

${ }^{41}$ Richmond County Economic Development. "Enviva, Wood Pellet Manufacturer to Open Richmond County Facility. The Company Will Invest $\$ 107$ Million and Create 79 Jobs," (September 9, 2014).
} 
FIG. 2. Percentage poverty, all ages, by county.

FIG. 3. Environmental justice communities and wood pellet production facilities in the southeastern United States.
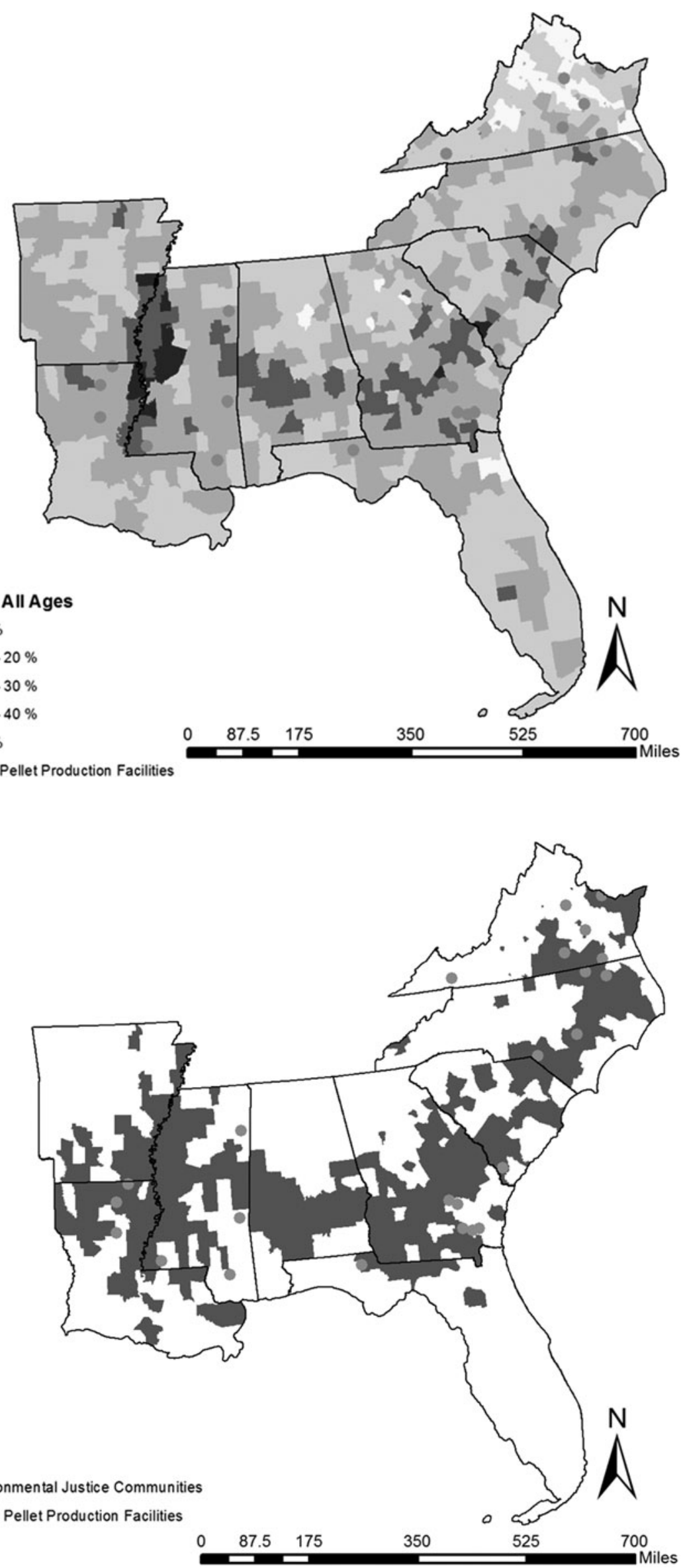
percentiles for traffic proximity, Superfund site proximity, ozone, PM 2.5, and air toxics cancer risk among minority and low-income communities. ${ }^{42}$ The Concerned Citizens of Richmond County, a grassroots community organization, rallied against the siting of the plant, stating that, along with a freight train station, natural gas pipeline, chicken processing facility, and natural gas-fired power plant in the county, the "Enviva plant is an additional injustice in our community." "43 The median poverty line in North Carolina is $20.15 \%$, whereas in Richmond County it is $27.3 \%$. The percentage nonwhite population in the county stands at $37.5 \%$. Richmond County, using our already stated criteria, is designated as an EJ community.

County residents raised concerns regarding the noise, traffic congestion, and air pollution that the wood pellet production facility will bring with it. Sadly, residents' objections to the siting of the plant in Richmond County have not been heard, as county commissioners repeatedly denied residents the opportunity to speak publicly before the commission. ${ }^{44}$

In addition, it is contested that the original air permit for the plant was issued without an opportunity for public comment on the part of the community. The Southern Environmental Law Center filed a petition in May 2017 with the Department of Environmental Quality (DEQ), arguing that the DEQ failed to "correct the deficient public notice and improper denial of a public hearing that accompanied the original draft permit." ${ }^{45}$ The case in Hamlet, North Carolina, represents a classic case of EJ denied by distributive, procedural, and process-orientated standards of justice.

\section{CONCLUSION}

Those fighting for EJ celebrate North Carolina as the birthplace of the EJ movement in the 1980s. As this ar- ticle has shown, North Carolina and much of the southeastern United States remain at the center of the fight for just and healthy communities. Wood pellet production facilities are found predominantly in the southeastern United States. The southeast produces more than 12 million tons of biomass pellets in 2017, with those estimates expected to rise. $^{46}$ These plants emit significant levels of carbon monoxide, carbon dioxide, nitrogen oxides, sulfur oxides, and particulate matter. Harmful airborne pollutants threaten public health, particularly in the young and elderly.

By defining EJ communities as communities with high levels of poverty and large nonwhite populations, we showed that they are roughly $50 \%$ more likely than nonEJ communities to have a biomass pellet facility located in their community. In addition, North and South Carolina had wood pellet production facilities located exclusively in EJ communities. A contemporary instance of a biomass wood pellet production facility being placed in an EJ community is illustrated by our example of Richmond County, North Carolina, showing that residents' right to EJ is being denied. This research details the continued pattern of energy projects and development being sited in areas where communities are economically, politically, and socially marginalized.

\section{AUTHOR DISCLOSURE STATEMENT}

No competing financial interests exist.

Address correspondence to: Sam Davis Dogwood Alliance PO Box 7645 Asheville, NC 28802

E-mail: sam@dogwoodalliance.org

\footnotetext{
${ }^{42}$ U.S. Environmental Protection Agency, EJSCREEN. (Last accessed on August 26, 2017).

${ }^{43}$ Emily Zucchino. "Richmond Country Residents Oppose Enviva Mill and Rally for Health and Environmental Justice." Dogwood Alliance Blog Post (April 6, 2017).

${ }^{44}$ Lisa Sorg. "Richmond County Commission's Public Comment Policy Has Violated First Amendment-For 20 Years." NC Policy Watch, (March 13, 2017).

${ }^{45}$ Southern Environmental Law Center, "N.C. Citizens Group, SELC Challenge Permit for Polluter Issued Without Public Notice." <https://www.southernenvironment.org/newsand-press/news-feed/n.c.-citizens-group-selc-challenge-permitfor-polluter-issued-without-publi>. (Last accessed on August 28 , 2017).
}

\footnotetext{
${ }^{46}$ United States Energy Information Administration. Monthly Densified Biomass Fuel Report. <https://www.eia.gov/biofuels/ biomass $>$. (Last accessed on June 21, 2017).
} 